\title{
What Leadership Looks Like in Different Cultures
}

\author{
Xiaotian $\mathrm{Guo}^{1 *}$, Jinghan $\mathrm{Liu}^{2}$, Minghe Wang ${ }^{3}, \mathrm{Yu} \mathrm{Liao}^{4}$
}

\author{
${ }^{1}$ Asian-Australian Business College, Liaoning University, Shenyang, Liaoning 110036, China*Corresponding author. \\ Email:931510924@qq.com \\ ${ }_{2}^{2}$ School of English, Hebei International Studies University, Shijiazhuang, Hebei 050020, China*Corresponding \\ author. Email: 347213507@qq.com \\ ${ }^{3}$ Canada British Columbia Hefei NO.1 high school, Hefei, Anhui 230091, China *Corresponding author. Email: \\ 1979810974@qq.com \\ ${ }^{4}$ HangZhouShangHaiworldforaginschool, Hangzhou, Zhejiang 310000, China *Corresponding author. Email: \\ ly13345998081@qq.com
}

\begin{abstract}
Leadership is recognized as an important function of management in the world, but its definition is various in different cultural backgrounds. These differences can be reflected in power distance latitude, individuality, uncertainty avoidance, and so on. This paper will discuss the different ways of leadership in different regions and cultural backgrounds through examples from several countries. Under the framework proposed by Greet Hofstede, the article takes China, South Korea, the United States, and France as examples to discuss the different power distances between the West and the East. Power distance represents the assumption and acceptance of an unfair proportion of power, resources, and privilege among social members. By analyzing the advantages and disadvantages of leadership in these different backgrounds, this paper puts forward some ideas about leadership and management, which are suitable for the international situation of cultural integration.
\end{abstract}

Keywords: Cultural Background, Power Distances, Hofstede, The east and the west

\section{INTRODUCTION}

The new Millennium has set the stage for the changing world, and the importance of leadership cannot be stressed more in today's rapid-fire challenges. Leadership has been valued as early as in ancient times and exists as an important quality of all walks of life. Leadership is not geographical. In both the East and the West, success is not accompanied alone without leadership. Leadership is also everywhere. Not only do celebrities or CEOs in Fortune 500 companies embrace leadership, but ordinary people are also taking it as one of the most important characteristics. This paper will discuss the different ways in which leadership is embodied in different regions and cultural backgrounds with examples from several countries.

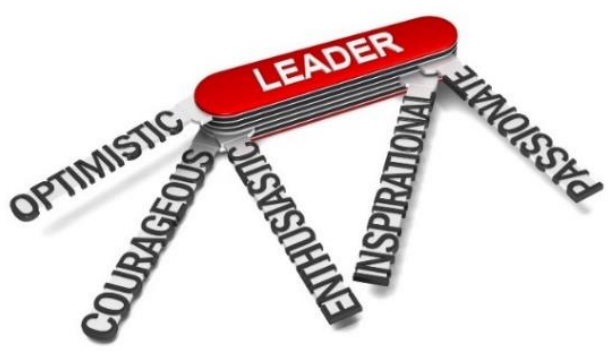

Figure 1 Leader [6]

\section{THE CULTURAL CONTEXT OF LEADERSHIP}

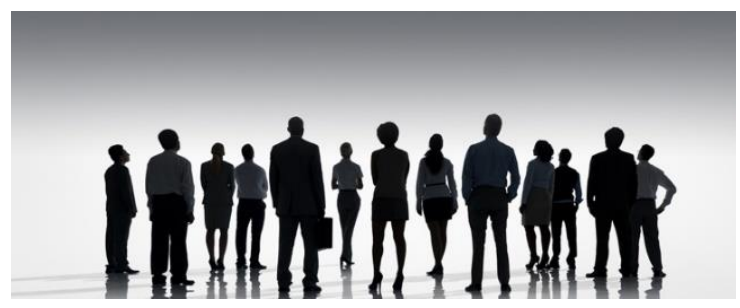

Figure 2 Leadership [7] 
Leadership is the capacity of sufficient application of manpower and objective element to achieve the efficiency of the total organization within the scope of jurisdiction at minimum cost. It is also seen as some attributes of a leader, such as personal qualities, the way of thinking, living experience, and methods of leading. Perhaps no topic has been studied, dissected, and discussed in more detail than leadership. In both academies and industries, leadership is well studied and discussed in a very long history.

For example, Yang Zhuang, a management professor at the National School of Development at Peking University, said, "Leadership is the temperament of employees themselves, while leadership is a right given by the outside world." British Field Marshal Bernard Montgomery once said: "Leadership is the ability and willpower to rally people around a common goal and the quality and character that inspires confidence." Some people have summarized leadership as a group of forces, a combination of forces [1]. However, no matter from what angle, real leadership has nothing to do with greedy actions such as giving orders, overriding others, and egoism, but with the virtual but real factors that transmit influence such as personality, pattern, and mind.

The definition and perception of leadership vary widely from culture to culture. Confucius, the ancient Chinese philosopher, advocated the "gentleman personality" of benevolence, wisdom, courage, integrity, mind, and responsibility. He said so and did so as well. Confucius' vision of the big picture also enabled him to gain powerful leadership. Unlike those, whose leadership is often followed by wealth, fame, and power, Confucius, in his poorest days, still have many students, such as Yan Hui and $\mathrm{Zi} \mathrm{Lu}$, who followed around and consulted respectfully. This is a full demonstration of the leadership of Confucius. Throughout history, Confucius's influence has spanned thousands of years and has inspired not only Chinese people but the whole world today. For leaders, Confucius believed that the most important thing was to have excellent character and strict requirements on their own words and deeds. Secondly, leaders should know how to be flexible in dealing with problems, do not treat people and love with personal resentment, treat subordinates with kindness, work and entrepreneurship should have a solid basic skill, master the ability to drive the overall situation. Confucius has a huge impact on how the Chinese define leadership. For example, the Chinese believe that leaders, no matter what his/her ability is, should be "gentleman" first. Leaders themselves should have a positive character - honesty, respect, responsibility, caring, and other good traits. This is a belief brought about by Confucian culture, However, in other cultures, leadership is defined as the outstanding personal ability, charisma, or appeal. What works for corporate in America may not work for the rest of the world. Similarly, what is seen as an advantage in one culture can be quite a barrier in another. For example, many attributes associated with charisma are thought to contribute to great leadership, but the word "charisma" arouses ambivalence in some areas. In addition, people worry about focusing too much on the charismatic, people would lose balance and perspective. In some cultures, a person may need to take strong, decisive action to be seen as a leader, while in other cultures, a consultative and democratic approach may be the preferred method of exercising effective leadership [2].

\section{IMPORTANCE AND AIM OF STUDYING LEADERSHIP DIFFERENCES}

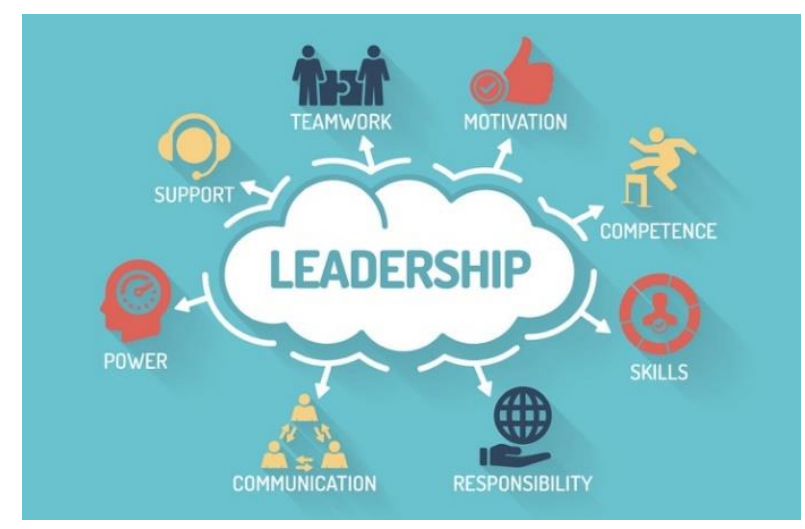

Figure 3 Leadership and Importance [8]

Leadership plays a vital role in any country, in any environment, in any social and cultural context. The study of leadership is a particularly indispensable task. Leadership in today's organizations faces many challenges, especially when facing multiple cultures. In western countries, leadership, one of the most widely studied structures in the field of management, can be defined as the most influential increment other than mechanical compliance with the conventional dictates of an organization. The ability to improve the efficiency of the entire organization at the minimum cost is a conventional understanding of leadership in the East. The purpose of leadership research is to "select the essence and discard the gross." The leadership culture produced in different cultural backgrounds will influence a country for a long time and gradually form the unique leadership template of each country. They also have their advantages. For example, the United States emphasizes winner's logic, technology, and rules; France emphasizes heroism and great leadership; China emphasizes "intelligent" leadership. Traditional Chinese culture emphasizes overall integration, ambiguity, intuitive insight, and dialectical connection, which provides sufficient spiritual nourishment for leaders. 


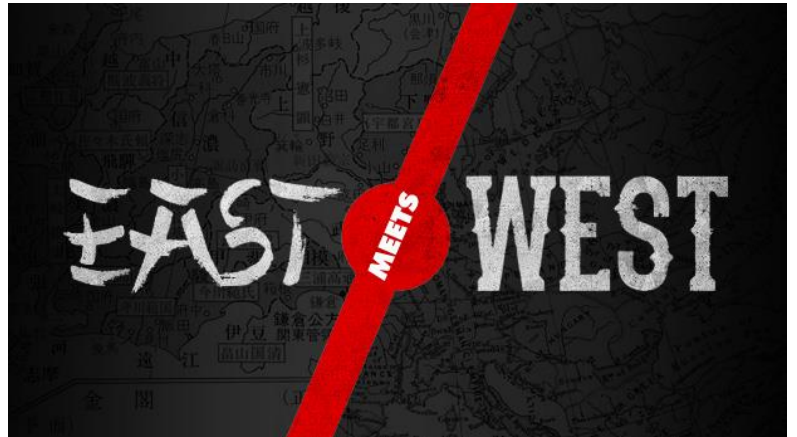

Figure 4 East and West [9]

The West pays more attention to local analysis, precision, and logical reasoning. Imagine that in an international company, it is obvious that the proper leadership system cannot be adopted. If people from different countries are forced to adapt to local leaders, it would harm the development of the company. Their cultural background is different, and the conflict is inevitable. In the process of research of leadership, leaders can take this opportunity to fully absorb foreign cultures and expand the cultural deposits of their own companies. With the gradual convergence of cultures around the world, business activities become globalized, with increasingly fierce competition and changes, which also puts forward requirements for diversified leadership. For example, the design of the organizational structure of multinational enterprises, the identification and selection of qualified leaders in specific cultures make them face employees with diverse cultures. It also works well in cross-border negotiations, sales, and mergers, and acquisitions. In the face of rapidly changing global competition, companies recognize the need and importance of empowerment (or low power distance), employee care and transformational (or energy) leadership, and cross-cultural adaptation. That's what studying leadership under the different cultural contexts is all about.

\section{POWER DISTANCE AND EXAMPLES}

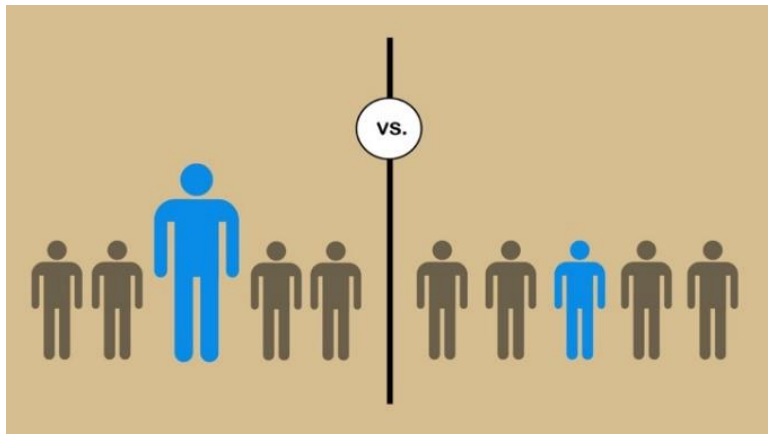

Figure 5 Power Distance [10]

To identify, quantify, and understand invisible cultural forces, Dutch social psychologist Geert Hofstede put forward a framework to discriminate the different cultures. They are power distance, individuals, masculinity, uncertainty avoidance, long-term orientation, indulgence, and restraint. In this paper, we discuss the different power distances between the West and the East.

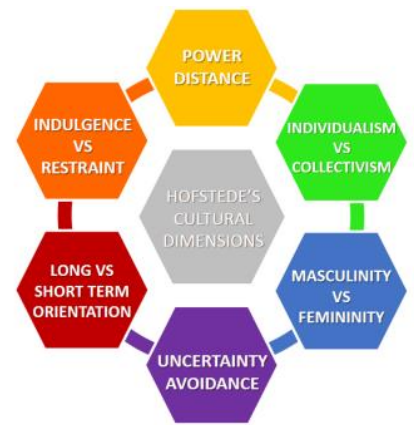

Figure 5 Hofstede's Cultural Dimensions [11]

Power distance represents the degree to which the members of society supposes and receive an unfair proportion of power, resources, and privileges. Many social institutions communities and organizations such as companies, families, schools, and government reflect different power distances. According to distinct cultural backgrounds, we divide power distance from high power distance and low power distance. Based on research by Hofstede, high power distance with great respect to authority and large probability accepts an uneven distribution of power while low power distance questions authority and be willing to take part in the decisions that influence themselves. The working relationship between managers and their subordinates is dependent on the power distance of the culture [3], which is defined by Hofstede as "the extent to which the less powerful members of organizations and institutions accept and expect that power is distributed unequally" [4]. In the eastern culture, the employees prefer to high power distance than the western culture. Whatever the manager command is, they will try their best to finish their job. They are guided to be obedient and respectful. However, whoever is under the low power distance leadership may challenge their bosses, and do not comply with all the work rules.

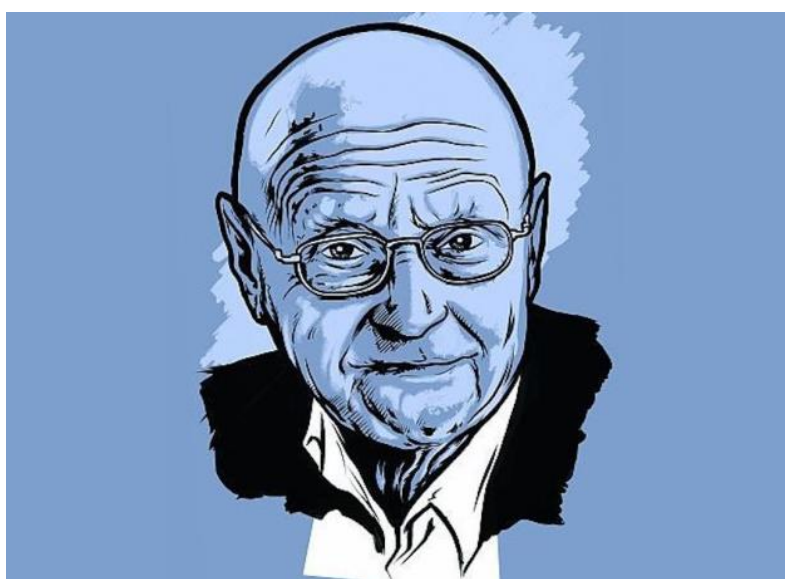

Figure 6 Hofstede [12] 
According to Hofstede and Hofstede [5], China scores high on the power distance index: 80 points compared to a world average of 56.5. In contrast, the United States is considered to with a low power distance index of 40 . The Chinese culture measures high on the power distance scale compare to most western countries such as the United States but not as high as Korea. The power distance even shows apparently on language use. When the Korean people talk to the senior, even if he or she is a month older, they must use the language with a special word suffix, or it would not respect the senior. Each verb in Korean has a different word suffix level which represents the degree to you show your respect. This phenomenon is common even on campus, the freshman has to communicate sophomore with respect tones. The contemporary Chinese language does not use different tones to show the status between leaders and their followers. Chinese people also show their respect to their supervisions. They may call their last name with a manger or other titles. If the staff could not precisely understand the managers' idea, the workshop could not do a perfect job, and this will further affect the company's performance.

In a low power distance country like the United States, people are more independent of the power holder as parents, teachers, bosses, etc. They do not emphasize hierarchical layers in the career and are not easier to be accepted. High power distance makes a gap between the employees and employers which is good for administrating the firm and decreasing the probability of needless trouble. Low power distance leadership has a better relationship than high but it is easier to make conflict in the organization because everyone thinks that they have the right to do something.

\section{CONCLUSION}

Leadership is an important function of today's management which is recognized all around the world. However, as we analyzed above, it is defined differently in different cultural backgrounds. These differences can be reflected in the latitude of power distance, individual, masculinity, uncertainty avoidance, long-term orientation, indulgence, and restraint (a framework proposed by Dutch social psychologist Greet Hofstede). In this paper, we discussed different interpretations of leadership by people in different regions and the different relationships between leaders and employees in different countries under the framework proposed by Greet Hofstede. Meanwhile, this paper compares the East and West world with examples of China, South Korea, the United States and France. By analyzing the advantages and disadvantages of leadership in those different contexts, we propose some noteworthy ideas about leadership and management which apply to other countries. Different cultural backgrounds lead to different views and practices of leadership. No matter how important the role leadership is playing in the workplace, we should find its best role in human resource management.

\section{REFERENCES}

[1] Jiang zhibing (2013). Research on leadership promotion under the background of Chinese excellent traditional culture. Human resources social sciences.

[2] knowledge@Wharton. (1999). How Cultural Factors Affect Leadership. https://knowledge.wharton.upenn.edu/article/howcultural-factors-affect-leadership/

[3] Białas S. (2009). Power distance as a determinant of relations between managers and employees in enterprises with foreign capital. Journal of Intercultural Management. Vol. 1, No. 2, pp. 105$115105-115$.

[4] Hofstede G. H., Hofstede G. (2001). Culture's Consequences: Comparing Values, Behaviors, Institutions and Organizations Across Nations. Thousand Oaks, CA: Sage Publications, Inc. Singh \& Pereira. (2005). The Culturally Customized Website. Elsevier Butterworth-Heinemann.

[5] Hofstede G.H. A Six-Dimensional Model of Cultural Difference. https://geerthofstede.com/culture-geerthofstede-gert-jan-hofstede/6d-model-of-nationalculture/

[6] Figure1 Leader from cn.bing.com

[7] Figure 2 Leadership from cn.bing.com

[8] Figure 3 Leadership and Importance from cn.bing.com

[9] Figure 4 East and West from cn.bing.com

[10] Figure 5 Power Distance from cn.bing.com

[11] Figure 5 Hofstede's Cultural Dimensions from cn.bing.com

[12] Figure 6 Hofstede from cn.bing.com 